\title{
Uso do Abate Comparativo na Determinação da Exigência de Energia de Mantença de Gado de Corte Pastejando Capim-Elefante: Descrição da Metodologia e dos Resultados
}

\author{
Carlos Augusto de Alencar Fontes ${ }^{1}$, Rildon Carlos de Oliveira ${ }^{2}$, Eleonora D'Ávila Erbesdobler ${ }^{3}$, \\ Domingos Sávio de Queiroz ${ }^{4}$
}

\begin{abstract}
RESUMO - Determinou-se o requerimento líquido de energia de mantença de novilhos mantidos em regime exclusivo de pastejo, em capim-elefante (Pennisetum purpureum, Schum) cv. Napier. O experimento teve duração de 175 dias, utilizando-se nove piquetes, estabelecidos em terreno plano, com área individual de 0,5 ha, sob pastejo rotacionado. Foram utilizados 36 novilhos $3 / 4 \mathrm{Gir}-\mathrm{Holandês} \mathrm{com}$ $332 \pm 37 \mathrm{~kg}$ e média de 20 meses de idade inicial. Metade dos animais teve o tempo de pastejo restrito a quatro horas por dia, de forma a se limitar o consumo de energia a pouco acima do nível de mantença, e metade teve acesso irrestrito à pastagem. Seis novilhos foram abatidos no início do experimento, para se determinar a composição corporal inicial (grupo referência) e seis (três de cada tratamento) a intervalos sucessivos de 35 dias. A composição corporal dos animais abatidos foi determinada por análise química de amostras representativas de todo o corpo. As exigências líquidas de energia para mantença foram estimadas como o calor produzido em nível zero de ingestão de energia metabolizável, ajustando-se equações do logaritmo da produção de calor em função do consumo de energia metabolizável, por dia e por unidade de tamanho metabólico $\left(\mathrm{kg}^{0,75}\right)$. Foi ajustada uma equação, calculando-se o tamanho metabólico em função do peso vivo (PV) e outra em função do peso de corpo vazio (PCVZ). O consumo e a digestibilidade da forragem ingerida (extrusa) foram determinados mensalmente. O tempo de pastejo limitado a quatro horas diárias assegurou ingestão de energia em nível pouco acima da mantença, conforme indicaram os ganhos de peso individuais, evidenciando que este procedimento pode ser recomendado para trabalhos futuros. A exigência de energia de mantença encontrada foi de $57 \mathrm{kcal} / \mathrm{kg} \mathrm{PV}^{0,75}$ ou 63,27 kcal/kg PCVZ ${ }^{0,75}$. Os valores obtidos estão dentro da faixa de resultados obtidos no Brasil, sendo mais baixos que os valores recomendados no exterior, para gado europeu.
\end{abstract}

Palavras-chave: descrição de metodologia, energia, exigências de mantença, novilhos, regime de pastejo

\section{Use of Comparative Slaughter to Set Maintenance Energy Requirements of Beef Cattle Grazing Elephantgrass: Description of Methodology and Results}

\begin{abstract}
The maintenance net energy requirement of steers grazing elephangrass (Pennisetum purpureum, Schum) cv. Napier, as unique food, was determined. The trial lasted 175 days. Nine 0.5 ha paddocks were implanted in flat-land, in rotational grazing, were used. Thirty-six 3/4 Gyr-Holstein steers averaging initial age of 20 months and $332 \pm 37 \mathrm{~kg}$ body weight (BW) were used. Half of animals had grazing time restricted to four hours daily, to limit energy intake at a level close to maintenance, and half had free access to pasture. Six steers were slaughtered at the beginning of trial to determine initial body composition (reference group), and six were slaughtered each 35 days. Body composition was determined by chemical analysis of representative samples of all animal body. The net energy maintenance requirements were estimated as heat production at zero level of metabolizable energy intake, regressing log heat production on metabolizable energy intake, per day and per unit metabolic size. Two equations were fitted: for the first, metabolic size was calculated as a function of body weight $\left(\mathrm{BW}^{0.75}\right)$ and for the second as function of empty body weight (EBW $\left.{ }^{0.75}\right)$. Forage intake and digestibility of forage consumed (extrusa) were determined monthly. The grazing time restricted to four hours a day allowed intake of energy at level close to maintenance as indicated the individual weight gains, showing that the procedure used in this research might be used in future trials. The net energy maintenance requirement observed was $57 \mathrm{kcal} / \mathrm{kg} \mathrm{LW}^{0.75}$ or $63,27 \mathrm{kcal} / \mathrm{kg} \mathrm{EBW}^{0.75}$. The values obtained fall into the range of values observed in Brazil and were lower than those recommended abroad for European type cattle.
\end{abstract}

Key Words: description of methodology, energy, grazing conditions, maintenance requeriments, steers

\section{Introdução}

O requerimento de energia de mantença tem sido definido como a quantidade de energia alimentar ingerida que não resulta em acréscimo ou perda de energia nos tecidos corporais do animal. É a energia necessária para os processos ou funções ligados à regulação da temperatura corporal, aos processos metabólicos essenciais e à atividade física (NRC,1996). No rebanho de corte, as exigências de mantença das vacas representam cerca de $70 \%$ da energia por elas consumida, anualmente, incluindo-se a energia gasta

\footnotetext{
${ }^{1}$ Professor Titular, PhD - Universidade Estadual do Norte Fluminense. Pesquisador CNPq. E.mail: cafontes@uenf.br

2 Zootecnista, M.Sc. - Autônomo

3 Zootecnista, M.Sc. - Aluna do curso de Pós-Graduação em Biociências - UENF.

${ }^{4}$ Pesquisador da EPAMIG - D. Sc.
} 
com a gestação e a lactação (Ferrell \& Jenkins,1985) e a cerca de $50 \%$ da energia total gasta na produção de animais de abate (Ferrell \& Jenkins, 1984).

Lofgreen \& Garrett (1968) estimaram as exigências de mantença de novilhas e machos castrados em $77 \mathrm{kcal} / \mathrm{PV}^{0,75}$. Esse valor foi adotado pelo NRC $(1984,1996)$ para bovinos de corte em crescimento. O ARC (1980), com base nos métodos calorimétricos, estimou essas exigências em 0,53 MJ/PV ${ }^{0,67}$.

Os requerimentos energéticos para mantença variam entre animais, em função da raça, do sexo e da idade (Noller \& Moe, 1995). Diferenças genéticas podem ocasionar mudanças de 20 a 30\% nos requerimentos, sendo a característica moderada a altamente herdável (Taylor \& Young, 1968). Entre diferentes raças, ocorrem correlações positivas do nível de exigência de energia de mantença com o potencial genético de produção de leite e com a taxa de crescimento (Ferrell \& Jenkins, 1985; Taylor et al.,1986)

Parte das diferenças nas exigências de mantença entre raças deve-se a variações nos tamanhos relativos dos tecidos ou órgãos do corpo. A atividade metabólica da proteína corporal é muito mais intensa que a do tecido adiposo, o que tende a elevar as exigências de energia de mantença, por unidade de tamanho metabólico, em animais com maiores proporções de músculos ou de menor maturidade fisiológica (Garrett,1980). Além disso, conforme salientado por Smith \& Baldwin (1973), o fígado, o coração, as glândulas mamárias e os tecidos do trato gastrintestinal incluem-se entre os componentes corporais de maior atividade metabólica dos animais. Seu tamanho é maior em bovinos leiteiros, o que explicaria suas maiores exigências de energia de mantença, por unidade de tamanho metabólico, em relação aos bovinos de corte.

O NRC (1996) estima que animais zebuínos em crescimento têm requerimentos de energia de mantença, por unidade de tamanho metabólico, aproximadamente $10 \%$ menores que os dos taurinos de raças de corte, os quais, por sua vez, têm requerimentos cerca de $20 \%$ menores que taurinos de raças de leite. Para o CNCPS (Fox et al., 1992), os requerimentos de mantença de animais zebuínos correspondem a $89 \%$ do valor básico $77 \mathrm{kcal} / \mathrm{PV}^{0,75}$ recomendado pelo NRC (1996).

Requerimentos de energia de mantença 20\% menores para animais zebuínos que para taurinos, foram relatados por Mullick \& Keas, em 1952, citados por Patle \& Mudgal (1975). Essa diferença é admitida pelas normas da CSIRO (1990), que recomenda, para zebuínos, níveis de energia de mantença 20\% menores que para taurinos de corte.

O sexo do animal é outro fator que influencia o nível de exigência de energia de mantença. Para um mesmo peso vivo, bovinos não-castrados têm maiores exigências de mantença que castrados e fêmeas, em função de seu maior conteúdo e reciclagem da proteína corporal, conforme descrito em revisão do NRC (1996). Esse fato é também reconhecido pelo ARC (1980) e o CSIRO (1990), que indicam para machos nãocastrados níveis de energia de mantença 15\% acima dos recomendados para machos castrados e fêmeas de mesmo peso corporal.

O Brasil não possui ainda normas nacionais de exigências nutricionais de bovinos de corte, conforme salientado por Silva et al. (2002). Entretanto, um volume crescente de pesquisas vem sendo desenvolvido, no intuito de se estabelecer as exigências, adaptadas aos animais e ao grau de acabamento (composição corporal) prevalentes.

As pesquisas realizadas no Brasil indicam, de forma inequívoca, que os requerimentos de energia para mantença de animais zebuínos são significativamente mais baixos que o valor $77 \mathrm{kcal} / \mathrm{PV}^{0,75}$, proposto por Lofgreen \& Garrett (1968). Assim, Salvador (1980) encontrou, para novilhos azebuados, exigências de $56 \mathrm{kcal} / \mathrm{PV}^{0,75}$. Em trabalhos posteriores, Gonçalves et al. (1991), Pires et al. (1993), Boin (1995) e Freitas et al. (2000), expressando o peso do animal em peso de corpo vazio (PCVZ), verificaram, para animais zebuínos, exigências de 59,77; 34,17; 69,8 e 50,22 kcal/ PCVZ ${ }^{0,75}$, respectivamente. Por sua vez, Paulino et al. (1999) encontraram, para animais nãocastrados das raças Nelore, Gir, Guzerá e Mocho de Tabapuã, tomados em conjunto, exigências de 60,4 kcal/PCVZ ${ }^{0,75}$, enquanto Paulino et al. (2004) encontraram exigência de $71,4 \mathrm{~kg} / \mathrm{PCVZ}^{0,75}$, para animais anelorados.

Três métodos têm sido utilizado para se determinar as exigências de energia de mantença dos bovinos: 1 - experimentos de longo termo, para determinação do nível de alimentação necessário para manutenção de peso constante; 2 - métodos calorimétricos; 3 - método do abate comparativo. O último método foi o adotado no Sistema Californiano de Energia Líquida, que serviu como base para o NRC $(1976,1984,1996)$, e tem a vantagem sobre o método calorimétrico de 
permitir a determinação das exigências em condições mais próximas às de exploração dos animais, não apresentando, ao mesmo tempo, as limitações que os experimentos de longo termo têm para emprego de animais em fase de crescimento, em gestação ou em lactação (NRC, 1996).

Os estudos de exigências nutricionais têm sido conduzidos em regime de confinamento, em decorrência da facilidade de se determinar com boa precisão o consumo alimentar dos animais. Entretanto, seria desejável determinar as exigências em condições idênticas àquelas em que o animal é explorado comercialmente, ou seja, em regime de pastejo, no caso da produção pecuária brasileira. Além disso, o estudo das exigências nutricionais poderia ser associado à determinação do conteúdo de energia líquida para mantença e do ganho de peso da forrageira, em condição de pastejo, em que o animal pode exercer a seletividade do alimento em grau muito mais pronunciado que quando recebe a forrageira no cocho.

Esta pesquisa foi conduzida com os objetivos de estabelecer uma metodologia para o estudo das exigências de energia de mantença de bovinos de corte, em regime de pastejo, utilizando-se a técnica de abate comparativo, e determinar as exigências de mantença de novilhos azebuados, em regime exclusivo de pastejo.

\section{Material e Métodos}

A pesquisa foi realizada na Fazenda Experimental da EPAMIG, em Leopoldina, MG e teve duração de 175 dias, coincidindo com o período chuvoso, que se estende, na região, de outubro a maio. O clima local, segundo a classificação de Köeppen (1948), é o Aw, que corresponde a clima tropical úmido, com inverno seco, verão chuvoso e temperatura média do mês mais frio superior a $18^{\circ} \mathrm{C}$.

Utilizou-se a técnica comparativa de abate, determinando-se o requerimento de mantença segundo metodologia descrita por Lofgreen \& Garrett (1968).

Foram utilizados 36 bovinos machos castrados, 3/4Gir-Holandês, criados em regime exclusivo de pastejo, com média de 20 meses de idade e peso vivo inicial de $332 \pm 37 \mathrm{~kg}$, selecionados entre 60 animais, em função da composição genética, da idade e do peso, escolhendo-se, ao mesmo tempo, animais com condição corporal semelhante.

Os novilhos foram mantidos em pastagem de capim-elefante (Pennisetum purpureum, Schum.) cv. Napier, com suplementação mineral. Adotou-se o pastejo rotacionado, com quatro dias de ocupação e 32 dias de descanso, utilizando-se nove piquetes, com área individual de 0,5 ha, estabelecidos em área plana.

Os animais foram divididos em três blocos, compostos por 12 animais cada, de acordo com o peso inicial. A seguir, dois animais de cada bloco foram alocados, aleatoriamente, em seis grupos de abate, ficando cada grupo constituído por seis animais. Um dos grupos foi abatido no início do experimento (grupo referência - GR).

A relação média entre o peso de corpo vazio (PCVZ) e peso vivo (PV) determinada nos animais GR foi utilizada para se estimar o PCVZ inicial dos animais remanescentes. Do mesmo modo, a composição média corporal dos animais de cada bloco do grupo referência (teores de proteína, gordura, cinzas, energia e água) foi utilizada como estimativa da composição corporal inicial dos animais restantes.

Os cinco grupos de animais experimentais remanescentes foram designados, por sorteio, para o abate em intervalos de 35 dias, constituindo os grupos de abate $A_{1}, A_{2}, A_{3}, A_{4}$ e $A_{5}$, abatidos aos 35, 70, 105, 140 e 175 dias, respectivamente, após o início do experimento, após pesagem precedida de jejum de 16 horas.

Três animais de cada grupo de abate, um de cada bloco, foram designados por sorteio, para receberem os tratamentos:

1. Pastejo ad libitum até o abate (AL);

2. Pastejo restrito (PR), de forma a se manter o consumo de energia próximo ao nível de mantença, com pequeno ganho de peso.

Os animais PR tiveram acesso à pastagem durante 4 horas diárias ( 6 às 10 h), admitindo-se que esse tempo de pastejo permitiria a ingestão de alimento em nível acima da mantença, conforme determinações preliminares feitas pelos autores, antes do início da pesquisa. Após o tempo de pastejo, esses novilhos permaneceram o resto do dia em currais dotados de área coberta, com acesso à água. Os animais AL foram mantidos durante todo o dia na pastagem, tendo acesso, a cada dia, aos mesmos piquetes dos animais PR.

Optou-se por fazer a restrição alimentar por meio do tempo de pastejo, em vez de se aumentar a pressão de pastejo em área separada, para se garantir que os novilhos dos dois tratamentos tivessem acesso à mesma pastagem, durante todo o experimento, ingerindo 
alimento de mesma digestibilidade e concentração de energia metabolizável.

Os animais já vinham sendo mantidos em pastagens de capim-elefante antes do período experimental, sendo colocados nos piquetes experimentais sete dias antes do abate inicial.

Durante o período experimental, procurou-se manter taxa de lotação equivalente a 5,5 animais por ha. No cálculo inicial da taxa de lotação, admitiu-se que um animal do tratamento 1 , pastejando ad libitum, teria ganho de peso médio de 500 a $600 \mathrm{~g}$ por dia, durante o experimento, ingerindo alimento correspondente a aproximadamente 1,6 vezes a exigência de mantença. Desta forma, cada animal do tratamento 2 (PR) ingerindo alimento em nível próximo à mantença, corresponderia, aproximadamente, a 0,625 animal do tratamento 1 ( $1 \mathrm{x}$ mant/1,6 x mantença $=0,625)$. Os novilhos abatidos eram imediatamente substituídos por animais com peso vivo e de composição genética semelhantes, procurando-se manter constante a pressão de pastejo.

A disponibilidade de forragem no início do período de ocupação dos piquetes foi determinada dez vezes durante o período experimental, lançando-se, aleatoriamente, um quadrado de $3 \mathrm{~m}^{2}$ dez vezes no piquete. A forragem contida no quadrado era cortada a $10 \mathrm{~cm}$ do solo, fazendo-se a separação do material vivo em lâminas foliares e bainha + colmo, conforme descrito por Erbesdobler et al. (2002), em estudo paralelo, envolvendo os mesmos animais e piquetes.

O consumo alimentar individual foi estimado seis vezes durante o período experimental, utilizando-se a relação produção fecal/indigestibilidade da matéria seca alimentar. A produção fecal foi determinada utilizando-se o indicador óxido crômico. Em cada determinação, $5 \mathrm{~g}$ de $\mathrm{Cr}_{2} \mathrm{O}_{3}$ foram fornecidos a cada novilho, duas vezes ao dia, às 10 e $15 \mathrm{~h}$, acondicionados em cartucho de papel, que era colocado diretamente no esôfago do animal, durante 16 dias consecutivos. Após os primeiros oito dias (período de padronização), iniciou-se o período de amostragem, com duração de oito dias, em que amostras fecais foram obtidas por coleta retal, duas vezes ao dia, no momento de fornecimento do $\mathrm{Cr}_{2} \mathrm{O}_{3}$.

As amostras individuais de fezes foram colocadas em sacos plásticos e, ao final do período de coleta, foram misturadas, obtendo-se amostras compostas, por animal, por período de pastejo, que foram congeladas a $-15^{\circ} \mathrm{C}$, para posteriores análises laboratoriais.
As dosagens de cromo foram feitas pelo método colorimétrico, fazendo-se digestão nitro-perclórica e leitura em espectrofotômetro UV visível a $440 \mathrm{~nm}$ (aparelho SPEKOL UV visível).

As amostras da dieta foram obtidas durante os oito dias de coleta das amostras fecais (seis vezes durante o período experimental), utilizando-se quatro novilhos fistulados no esôfago, segundo a técnica descrita por Bishop \& Froseth (1970). As bolsas de coleta foram feitas de lona impermeável, contendo malha de náilon no fundo, para drenagem de saliva.

Nos dias de amostragem, os animais fistulados foram contidos e privados de alimento durante 12 horas. Após este período, foram removidas as cânulas e colocadas as bolsas de coleta, sendo os animais soltos para pastejarem, por 30 a 40 minutos, junto com os animais experimentais. As amostras obtidas foram agrupadas em amostras compostas, por animal, por período de coleta, e congeladas a $-15^{\circ} \mathrm{C}$, para posteriores análises laboratoriais.

A digestibilidade das extrusas foi determinada pelo método in vitro (Tilley \& Terry, 1963). O líquido de rúmen utilizado foi coletado de animal fistulado no rúmen, alimentado com capim-elefante, por um período mínimo de dez dias antes da referida coleta.

A produção fecal foi estimada utilizando-se a fórmula:

$$
\text { Cromo fornecido (g/dia) }
$$

Produção fecal =

$$
\text { Concentração de cromo }
$$$$
\text { nas fezes (g/g de MS) }
$$

O consumo individual diário de matéria seca (MS) foi estimado por meio da fórmula:

$$
\text { Produção fecal diária }
$$

Consumo diário de MS =

$$
100 \text { - digestibilidade da MS }
$$

As amostras de extrusa e fezes foram submetidas à secagem em estufa com ventilação forçada, a $55^{\circ} \mathrm{C}$ por 72 horas, e, a seguir, foram processadas em moinho tipo Willey com peneira de 30 mesh. Foram determinados os teores de matéria seca, proteína bruta (PB), fibra em detergente neutro (FDN) e matéria orgânica, além do conteúdo de energia bruta na extrusa e nas fezes, e a digestibilidade in vitro da 
matéria seca (DIVMS) da extrusa. Essas determinações foram feitas segundo metodologia descrita por Silva (1990).

Os consumos diários médios individuais de energia digestível (ED), em cada período de 35 dias, foram calculados a partir dos conteúdos de energia da extrusa e das amostras compostas individuais de fezes, bem como dos valores de consumo e excreção fecal individuais médios diários, no período. O consumo de energia metabolizável (EM) foi estimado utilizando-se a relação: $\mathrm{EM}=$ 0,82 x ED (NRC, 1996).

Para determinação da energia corporal retida pelos animais dos dois tratamentos, efetuou-se, ao abate, a pesagem e amostragem de todos os componentes corporais, para posterior determinação dos teores de proteína, gordura e água, de forma a se determinar a composição do corpo vazio (livre de digesta).

Os componentes do trato gastrintestinal (TGI) foram esvaziados, lavados e pesados, retirando-se amostras proporcionais ao peso de cada um, de forma a se constituir uma amostra representativa de todo o trato.

As amostras de língua, traquéia, esôfago, fígado, coração, rins, pulmões, baço, carne industrial e aparelho reprodutor foram agrupadas de forma proporcional, constituindo-se uma amostra composta de órgãos. De modo semelhante, as amostras de gordura cavitária e gordura visceral foram proporcionalmente reunidas, constituindo-se uma amostra composta de gordura interna. As amostras de couro e sangue, obtidas após pesagem dos dois tecidos, foram manipuladas de forma isolada.

Os pesos das cabeças, da cauda e dos pés de todos os animais foram igualmente anotados e, em cada abate, foram dissecados, pesados e amostrados os ossos e tecidos moles da cabeça, dos pés e da cauda de um animal de cada tratamento, tomando-se sua composição como representativa dos demais.

As duas meia-carcaças foram pesadas quentes e levadas à câmara fria, onde permaneceram por, aproximadamente, 18 horas a $-5^{\circ} \mathrm{C}$. Após esse tempo, foram coletadas amostras individuais da carcaça esquerda, correspondendo à seção da $9^{\mathrm{a}}$ à $11^{\mathrm{a}}$ costela (seção HH), segundo Hanskins \& Howe (1946). As seções foram dissecadas, determinando-se as proporções de músculo (carne), tecido adiposo e ossos nelas contidas.

As proporções de músculo, tecido adiposo e ossos da carcaça foram estimada com base nas proporções desses componentes na seção HH, por meio das equações abaixo, propostas por Hankins \& Howe (1946):
Músculos: $\quad \mathrm{Y}^{\prime}=16,08 \times 0,80 \mathrm{X}$

Tecido adiposo: $\quad \mathrm{Y}^{\prime}=3,54+0,80 \mathrm{X}$

Ossos: $\quad \mathrm{Y}^{\prime}=5,52+0,57 \mathrm{X}$

em que $\mathrm{X}$ é a porcentagem do componente na seção $\mathrm{HH}$.

As amostras de carne (120 g), tecido adiposo (200 g), vísceras (120 g) e composta de órgãos (200 g), após moídas, e as de couro, ossos e cauda (120g), após seccionadas, foram colocadas em vidros com capacidade de $500 \mathrm{~mL}$ e levadas à estufa a $105^{\circ} \mathrm{C}$, durante 72 a 96 horas, para determinação do teor de matéria seca gordurosa (MSG). Em seguida, foram submetidas a um processo de extração de gordura com éter de petróleo, conforme descrito por Kock \& Preston (1979), obtendo-se a matéria seca pré-desengordurada (MSPD). As amostras pré-desengorduradas foram, então, submetidas ao processamento em moinho de bola, antes de se proceder às determinações dos teores de nitrogênio e extrato etéreo.

As amostras de sangue (400 g) foram acondicionadas em pirex e levadas à estufa com ventilação forçada a $55-60^{\circ} \mathrm{C}$, durante 48 horas, para determinação da matéria pré-seca, e, em seguida, foram processadas em moinho de bola.

As análises de nitrogênio total foram feitas em aparelho semimicro Kjeldahl e as de extrato etéreo em aparelho Goldfish, conforme metodologia descrita por Silva (1990). O conteúdo de proteína foi determinado a partir do conteúdo de nitrogênio total utilizando-se o fator 6,25.

O conteúdo total de gordura da amostra foi obtido somando-se a gordura removida no prédesengorduramento com o extrato etéreo residual.

Os conteúdos de proteína e gordura no corpo vazio foram determinados somando-se seus conteúdos na carcaça, nos órgãos, nas vísceras, no sangue, no tecido adiposo interno, na cabeça, nos pés, na cauda e no couro.

A determinação do conteúdo corporal de energia foi feita a partir dos conteúdos corporais de proteína e gordura e dos respectivos equivalentes calóricos: 5,6405 e 9,3929 (ARC, 1980).

A retenção de energia dos animais dos dois tratamentos foi determinada subtraindo-se do conteúdo corporal final de energia, determinado após o abate de cada animal, o seu conteúdo inicial estimado de energia, que, por sua vez, foi calculado com base no peso vivo (PV) inicial do animal e na relação PV/PCVZ e composição corporal observados nos animais referência (abatidos no início do experimento), pertencen- 
tes ao mesmo bloco. A retenção diária de energia foi expressa por unidade de tamanho metabólico.

As produções diárias individuais de calor, por unidade de tamanho metabólico, foram determinadas subtraindo-se dos valores médios individuais diários de consumo de energia metabolizável a energia retida, ambos por unidade de tamanho metabólico.

As exigências de energia líquida para mantença (EL) foram determinadas pela regressão do logaritmo da produção de calor, em função do consumo de energia metabolizável (EM), em kcal/dia e unidade de tamanho metabólico, extrapolando-se a equação para o nível zero de consumo de EM, segundo o método descrito por Lofgreen \& Garrett (1968). O tamanho metabólico foi expresso das duas formas: $\mathrm{PV}^{0,75}$ e $\mathrm{PCVZ}^{0,75}$.

As análises estatísticas do consumo diário de matéria seca e do ganho de peso diário dos animais foram feitas de acordo com o modelo:

$$
\mathrm{Y}_{\mathrm{ijkl}}=\mu+\mathrm{T}_{\mathrm{i}}+\mathrm{B}_{\mathrm{j}}+\mathrm{P}_{\mathrm{k}}+\mathrm{TB}_{\mathrm{ij}}+\mathrm{TP}_{\mathrm{ik}}+\mathrm{e}_{\mathrm{ijkl}} \text {, }
$$

em que: $Y_{i j k l}=$ observação referente ao animal l, do tratamento $\mathrm{i}$, pertencente ao bloco j, no período de pastejo $\mathrm{k} ; \mathrm{T}_{\mathrm{i}}=$ efeito do tratamento $\mathrm{i}$, em que $\mathrm{i}=1-$ pastejo ad libitum e 2 - pastejo restrito; $\mathrm{B}_{\mathrm{j}}=$ efeito do bloco j, em que j = 1, 2 e 3; $\mathrm{TB}_{\mathrm{ij}}=$ efeito da interação entre o tratamento i e o bloco j; $\mathrm{TP}_{\mathrm{ik}}=$ efeito da interação entre o tratamento i e o período $\mathrm{k}$; $\mathrm{e}_{\mathrm{ijkl}}=$ erro aleatório associado a cada observação, pressuposto normalmente distribuído, com média zero e variância $\sigma^{2}$.

\section{Resultados e Discussão}

Os valores médios diários observados para consumo de matéria seca e ganho de peso dos animais dos dois tratamentos, nos cinco períodos de pastejo são apresentados na Tabela 1. A análise estatística revelou efeito de interação de tratamento e período $(\mathrm{P}<0,05)$ para consumo de matéria seca, não ocorrendo esse efeito para ganho de peso $(\mathrm{P}>0,05)$.

O consumo de forragem dos animais do tratamento 1 (pastejo ad libitum) correspondeu, em média, nos cinco períodos de pastejo (175 dias), a 1,61 vezes o verificado para os animais submetidos ao pastejo restrito, limitado a 4 horas por dia. Esse valor coincide com a premissa feita no início do experimento, ao se estabelecer a taxa de lotação de 5,5 animais por ha, de que um animal pastejando ad libitum equivale a 1,60 animais pastejando 4 horas por dia. Houve tendência de elevação do consumo dos animais do tratamento 1 ao longo dos períodos, o que esteve associado, basicamente, às variações na disponibilidade de forragem, conforme verificado por Erbesdobler et al. (2002), em estudo paralelo envolvendo os mesmos animais e piquetes.

Tabela 1 - Consumo diário médio de matéria seca (MS) e ganho diário médio de peso de corpo vazio (PCVZ) dos animais dos tratamentos $\mathrm{T}_{1}$ (pastejo ad libitum) e $\mathrm{T}_{2}$ (pastejo restrito), nos cinco períodos de pastejo e relação entre as médias de consumo e os dois tratamentos

Table 1 - Daily dry matter (DM) intake and daily empty body weight (EBW) gain of animals from treatments $T_{1}$ (ad libitum grazing) and $T_{2}$ (restricted grazing), during the five grazing periods, and intake means ratio for both treatments

\begin{tabular}{|c|c|c|c|c|c|c|}
\hline \multirow[t]{2}{*}{$\begin{array}{l}\text { Tratamento } \\
\text { Treatment }\end{array}$} & \multicolumn{5}{|c|}{$\begin{array}{l}\text { Período } \\
\text { Period }\end{array}$} & \multirow[t]{2}{*}{$\begin{array}{l}\text { Média } \\
\text { Averag }\end{array}$} \\
\hline & I & II & III & IV & $\mathrm{V}$ & \\
\hline \multicolumn{7}{|c|}{$\begin{array}{l}\text { Consumo de MS (kg/dia) } \\
\text { Dry matter intake (kg/day) }\end{array}$} \\
\hline $\begin{array}{l}\mathrm{T}_{1} \\
\mathrm{~T}_{2} \\
\text { Relação } \mathrm{T}_{1} / \mathrm{T}_{2}\end{array}$ & $\begin{array}{l}7,48^{\mathrm{cA}} \\
4,70^{\mathrm{bB}} \\
1,59\end{array}$ & $\begin{array}{l}7,77^{\mathrm{bcA}} \\
4,98^{\mathrm{abB}} \\
1,56\end{array}$ & $\begin{array}{l}7,98^{\mathrm{bcA}} \\
5,60^{\mathrm{aB}} \\
1,43\end{array}$ & $\begin{array}{l}8,55^{\mathrm{abA}} \\
5,48^{\mathrm{abB}} \\
1,56\end{array}$ & $\begin{array}{l}9,12^{\mathrm{aA}} \\
4,72^{\mathrm{abB}} \\
1,94\end{array}$ & $\begin{array}{l}8,18 \\
5,09 \\
1,61\end{array}$ \\
\hline
\end{tabular}

$T_{1} / T_{2}$ ratio

$\begin{array}{lcl}\mathrm{T}_{1} & 124,80 & 590,25 \\ \mathrm{~T}_{2} & -182,87 & 172,83 \\ \text { Média } & -29,03^{\mathrm{b}} & 381,54^{\mathrm{a}} \\ \text { Average } & & \end{array}$

Médias seguidas de letras minúsculas diferentes nas linhas e maiúsculas distintas nas colunas diferem entre si $(P<0,05)$ pelo teste de Newman-Keuls.

Means followed by different small letters in the rows and different capital letters in the columns differ $(P<0.05)$ by Newman-Keuls test. 
Os níveis de consumo dos animais do tratamento 1 proporcionaram ganho médio de peso moderado (516 g), durante os 175 dias de experimento. Verificou-se menor ganho no período I, o que, em parte, pode estar ligado à menor adaptação dos animais ao regime experimental, que incluiu o fornecimento de óxido crômico, mensalmente, por período de 16 dias. O estresse inicial gerado pela freqüente movimentação dos animais e sua contenção para fornecimento do óxido crômico é também o fator mais provável que determinou a ligeira perda de peso verificada nos animais do tratamento 2, no período I.

Os animais do tratamento 2 (pastejo restrito) ganharam em média 148,2 g por dia durante os 175 dias do experimento. Esse nível de ganho comprova que o consumo médio de matéria seca, proporcionado pelo período de pastejo restrito de 4 horas por dia, possibilitou a ingestão de energia em níveis pouco acima da exigência de mantença, além de ter permitido o acesso dos animais a alimento da mesma qualidade disponibilizada aos animais com acesso ad libitum ao pasto. Nos estudos de determinação de exigências de energia de mantença utilizando-se a técnica do abate comparativo, é necessário que os animais recebam pelo menos dois níveis de energia, sendo um próximo à exigência de mantença e outro mais elevado. Além disso, os animais dos dois tratamentos devem receber dieta de mesma metabolizabilidade. Essas duas condições foram alcançadas nesta pesquisa. Fica evidenciado, portanto, que a metodologia utilizada neste trabalho tem amplas possibilidades de emprego em estudos futuros, podendo-se ajustar o tempo de pastejo, de acordo com a qualidade da forrageira.

Efetuando-se a regressão do logaritmo da produção de calor (PC), em função do consumo de energia metabolizável (CEM), com base no peso vivo ( $\left.\mathrm{PV}^{0,75}\right)$, obteve-se a equação:

$\log \mathrm{PC}_{(\mathrm{PV})} 0,75=1,75346075+0,0022978 \times$ CEM; $\mathrm{r}^{2}=0,552(\mathrm{P}<0,001)$

Quando se fez a regressão em função do peso de corpo vazio $\left(\mathrm{PCVZ}^{0,75}\right)$, chegou-se à equação:

$\log \mathrm{PC}_{(\mathrm{PCVZ})} 0,75=1,801188273+0,00207381 \mathrm{X}$ CEM; $\mathrm{r}^{2}=0,594(\mathrm{P}<0,001)$

Extrapolando-se as duas equações para o nível zero de consumo de energia metabolizável, foram obtidas, respectivamente, as exigências diárias de energia líquida de mantença de $57 \mathrm{kcal} / \mathrm{kg} \mathrm{PV}^{0,75}$ e $63,3 \mathrm{kcal} / \mathrm{kg} \mathrm{PCVZ}^{0,75}$.

Os valores obtidos estão dentro do intervalo dos resultados verificados no Brasil para animais azebuados, zebuínos de raças puras e mestiços Europeu-Zebu.

Embora esta pesquisa tenha sido conduzida em condições de pastejo, pode-se admitir que os requerimentos para atividade física tenham sido de pequena magnitude, uma vez que os piquetes eram completamente planos e possuíam área de apenas 0,5 ha, apresentando boa densidade e estrutura da vegetação favorável à apreensão da forragem pelo animal.

Entre os resultados obtidos no Brasil, Freitas et al. (2000) encontraram exigências de energia líquida para mantença de 50,22; 58,62; 59,77 e 56,18 kcal/kg $\mathrm{PV}^{0,75}$ para animais Nelore, bimestiços, $\mathrm{F}_{1}$ HolandêsNelore e búfalos, respectivamente. Os resultados são muito próximos aos verificados neste estudo, embora esses autores tenham trabalhado com animais nãocastrados, que, segundo o ARC (1980) e o CSIRO (1990), teriam exigência de mantença 15\% maiores que machos castrados e fêmeas. Por outro lado, utilizaram animais confinados, que teriam menor requerimento para atividade física.

Paulino et al. (1999) encontraram, para animais zebuínos das raças Gir, Nelore, Guzerá e Mocho de Tabapuã, tomados em conjunto, exigências de mantença de $60,38 \mathrm{kcal} / \mathrm{kg} \mathrm{PV}^{0,75}$. Esse valor é $7,8 \%$ mais elevado que o obtido neste trabalho, mas os animais utilizados por esses autores eram nãocastrados e, portanto, possuíam maior exigência de energia de mantença. Trabalhando igualmente com animais não-castrados, Boin (1995) verificou exigência de $68,4 \mathrm{kcal} / \mathrm{kg} \mathrm{PV}^{0,75}$, cerca de $20 \%$ mais elevada que o resultado deste trabalho, para animais Nelore com 21 a 24 meses de idade. Valores mais elevados que os observados foram relatados por Paulino et al. (2004), que encontraram, para animais anelorados, exigência líquida de energia de $74,5 \mathrm{kcal} / \mathrm{PCVZ}^{0,75}$ ou $69,3 \mathrm{kcal} / \mathrm{PV}^{0,75}$.

Exigência de mantença, para animais azebuados castrados, de $56 \mathrm{kcal} / \mathrm{kg} \mathrm{PV}{ }^{0,75}$, muito próxima à encontrada nesta pesquisa, foi observada por Salvador (1980). De forma semelhante, Gonçalves et al. (1991) verificaram exigência de mantença de 
Tabela 2 - Exigências líquidas de energia para mantença, em Mcal/animal/dia, em função do peso vivo ou de peso de corpo vazio (PCVZ)

Table 2 - Net energy requirements for maintenance, in Mcal/ animal/day, according to body weight or empty body weight (EBW)

Peso vivo (kg) EL $\mathrm{m}_{\mathrm{m}}$ (Mcal/dia) PCVZ(kg) $\mathrm{EL}_{\mathrm{m}} \mathrm{Mcal} / \mathrm{dia}$

\begin{tabular}{llll}
\hline 300 & 4,11 & 250 & 3,98 \\
350 & 4,61 & 300 & 4,56 \\
400 & 5,10 & 350 & 5,12 \\
450 & 5,57 & 400 & 5,66 \\
500 & 6,02 & 450 & 6,18 \\
\hline
\end{tabular}

$59,77 \mathrm{kcal} / \mathrm{kg} \mathrm{PV}^{0,75}$, para animais Nelore castrados. Ressalta-se, entretanto, que esses autores trabalharam com animais confinados.

As exigências líquidas de energia para mantença $\left(E L_{m}\right)$, expressas em $\mathrm{Mcal} /$ animal/dia, estimadas a partir das equações obtidas neste trabalho, para animais com peso vivo de 300 a $500 \mathrm{~kg}$ e peso de corpo vazio de 250 a $450 \mathrm{~kg}$, encontram-se na Tabela 2.

Quando comparados aos valores de exigências de mantença encontrados no exterior para bovinos de raças européias, incluindo o valor consagrado de 77 kcal/ kg PV ${ }^{0,75}$, proposto por Loffgreen \& Garrett (1968) e adotado pelo NRC (1984), os resultados obtidos no Brasil, para animais zebuínos ou mestiços com predominância de raças zebuínas, e os valores encontrados neste estudo são mais baixos. Isto está de acordo com as observações de Patle \& Mudgal (1975) e CSIRO (1990) de que as exigências de mantença de animais zebuínos são cerca de $20 \%$ menores que aquelas dos taurinos.

As diferenças entre raças estão ligadas a fatores como reciclagem da proteína corporal, que é maior em animais de raças com maior massa muscular e em animais não-castrados, em relação a machos castrados e fêmeas (Garrett, 1980), sendo também altamente influenciadas pela massa de órgãos internos metabolicamente ativos (Smith \& Baldwin, 1973), que tende a ser maior em animais taurinos que em zebuínos (Ferrell et al., 1976) e em animais $F_{1}$ Europeu-Zebu que em zebuínos (Jorge, 1993).

\section{Conclusões}

A metodologia empregada neste trabalho mostrou-se adequada para o estudo das exigências de energia de mantença de bovinos de corte mantidos em regime de pastejo, tendo permitido limitar o consumo de forragem dos animais submetidos a pastejo restrito em nível pouco acima da exigência de mantença, mas garantindo a esses acesso à forragem de qualidade semelhante aos animais em pastejo ad libitum.

As exigências de mantença encontradas situaram-se dentro do intervalo dos resultados obtidos no Brasil, para animais zebuínos, azebuados e mestiços Europeu-Zebu, castrados e não-castrados. Foram, entretanto, inferiores aos valores preconizados pelo NRC (1996) para gado europeu.

\section{Literatura Citada}

AGRICULTURAL RESEARCH COUNCIL - ARC. The nutrient requirements of ruminants livestock. London: 1980. 351p.

BISHOP, J.C.; FROSETH, J.A. Improved techniques in esophageal fistulization of sheep. American Journal of Veterinarian Research, v.31, n.8, p.1505-1707, 1970.

BOIN, C. Alguns dados sobre exigências de energia e de proteína de zebuínos. In: SIMPÓSIO INTERNACIONAL SOBRE EXIGÊNCIAS NUTRICIONAIS DE RUMINANTES, 1995, Viçosa, MG. Anais... Viçosa, MG: JARD, 1995. p.457-465.

COMMONWEALTH SCIENTIFIC AND INDUSTRIAL RESEARCH ORGANIZATION - CSIRO. Feeding standards for Australian livestock-ruminants. Victoria: Australia Agricultural Council, 1990. 266p.

ERBESDOBLER, E.A.; FONTES, C.A.A.; QUEIROZ, D.S. et al. Avaliação do consumo e ganho de peso de novilhos em pastejo rotacionado de capim-elefante (Pennisetum purpureum, Schum.) cv. Napier, na estação chuvosa. Revista Brasileira de Zootecnia, v.5, p.2123-2128, 2002.

FERRELL, C.L.; JENKINS, T.G. Cow type and the nutritional environment: Nutritional aspects. Journal of Animal Science. v.61, n.3, p.725-741, 1985.

FERRELL, C.L.; JENKINS, T.G. Energy utilization by mature, nonpregnant, nonlactating cows of different types. Journal of Animal Science, v.58, n.1, p.234-243, 1984.

FERRELL, C.L.; GARRETT, W.N.; HINMAN, N. et al. Energy utilization by pregnant heifers. Journal of Animal Science, Champaign, v.42, n.4, p.937-950, apr, 1976

FOX, D.G.; SNIFFEN, C.J.; O'CONNOR, J.D. et al. A net carbohydrate and protein system for evaluating cattle diets: III. Cattle requirements and diet adequacy. Journal of Animal Science, v.70, n.11, p.3578-3596, 1992.

FREITAS, J.A.; FONTES, C.A.A.; SOARES, J.E. et al. Composição corporal e exigências de energia de mantença de bovinos (zebuínos e mestiços) e bubalinos não castrados, em confinamento. Arquivo de Ciências Veterinárias e Zoologia - Unipar, v.3, n.1, p.19-29, 2000.

GARRETT, W.N. Factors influencing energetic efficiency of beef production. Journal of Animal Science, v.51, n.6, p.1434-1440, 1980.

GONÇALVES, L.C.; SILVA, J.F.C.; VALADARES FILHO, S.C. et al. Exigências de energia para cinco grupos genéticos de novilhos. Revista Brasileira de Zootecnia, v.51, n.6, p.1434-1440, 1980. 
HANKINS, O.G.; HOWE, P.E. Estimation of the composition of beef carcasses and cuts. Washington, D.C., 1946. (Technical Bulletin - USDA, 926).

JORGE, A.M. Ganho de peso, conversão alimentar e características da carcaça de bovinos e bubalinos. Viçosa, MG: Universidade Federal de Viçosa, 1993. 97p. Dissertação (Mestrado em Zootecnia) - Universidade Federal de Viçosa, 1993.

KOCK, S.W.; PRESTON, R.L. Estimation of bovine carcass composition by the urea dilution technique. Journal of Animal Science, v.48, n.2, p.319-327, 1979.

KOËPPEN, W. Climatologia. Buenos Aires: Panamericana, 1948. 478p.

LOFGREEN, G.P.; GARRETT, W.N. A system for expressing net energy requeriments and feed values for growing and finishing beef cattle. Journal of Animal Science, v.27, n.3, p.793-806, 1968.

NATIONAL RESEARCH COUNCIL - NRC. Nutrient requirements of domestic animals, nutrient requeriments of beef cattle. 5.ed. Washington, D.C.: 1976. 56p.

NATIONAL RESEARCH COUNCIL - NRC. Nutrient requeriments of beef cattle. 6. ed. Washington, D.C.: 1984, 90p.

NATIONAL RESEARCH COUNCIL - NRC. Nutrient requirements of beef cattle. 7.ed. Washington, D.C.: 1996. 242p.

NOLLER, C.H.; MOE, P.W. Determination of NRC energy and protein requeriment for ruminants. In: PEREIRA, J.C. (Ed). SIMPÓSIO INTERNACIONAL SOBRE EXIGÊNCIAS NUTRICIONAIS DE RUMINANTES, 1995, Viçosa, MG. Anais... Viçosa, MG: Universidade Federal de Viçosa, 1995. p.53-76.

PATLE, B.R.; MUDGAL, V.D. Maintenance requeriments for energy in crossbred cows. British of Journal of Nutrition, v.33, n.1, p.127-32, 1975.

PAULINO, M.P.; FONTES, C.A.A.; JORGE, A.M. et al. Exigências de energia para mantença de bovinos zebuínos nãocastrados em confinamento. Revista Brasileira de Zootecnia, v.28, n.3, p.621-626, 1999.
PAULINO, P.V.R.; COSTA, M.A.L.; VALADARES FILHO, S.C. et al. Exigências nutricionais de zebuínos. Energia. Revista Brasileira de Zootecnia, v.32, p.781-791, 2004.

PIRES, C.C.; FONTES, C.A.A.; GALVÃO, J.G. et al. Exigências nutricionais de bovinos de corte em acabamento. II. Exigências de energia para mantença e ganho de peso. Revista da Sociedade Brasileira de Zootecnia, v.22, n.1, p.121-132, 1993.

SALVADOR, M. Exigências de energia e proteína para engorda de novilhos azebuados. Viçosa, MG: Universidade Federal de Viçosa, 1980. 70p. Dissertação (Mestrado em Zootecnia) - Universidade Federal de Viçosa, 1980.

SILVA, F.F.; VALADARES FILHO, S.C.; ÍTAVO, L.C.V. et al. Exigências líquidas e dietéticas de energia, proteína e macroelementos minerais de bovinos de corte no Brasil. Revista Brasileira de Zootecnia, v.31, n.2, p.776-792, 2002.

SILVA, D.J. Análise de alimentos (métodos químicos e biológicos). Viçosa, MG: Universidade Federal de Viçosa, 1990. $165 p$.

SMITH, N.E.; BALDWIN, R.L. Effects of breed, pregnancy and lactation on weight of organs ad tissues in dairy cattle. Journal of Dairy Science, v.57, n.9, p.1055-1060, 1973.

TAYLOR, St. C.S.; THIESSEN, R.B.; MURRAY, J. Interbred relationship of maintenance efficiency to milk yeld in cattle. Animal Production, v.43, n.1, p.37-61, 1986.

TAYLOR, St. C.S.; YOUNG, G.B. Equilibrium weight in relation to food intake and genotype in twin cattle. Animal Production, v.10, n.3, p.393-412, 1968.

TILLEY, J.M.A.; TERRY, R.A. A two-stage technique for the in vitro digestion of forage crops. Journal British Grassland Society, v.18, n.2, p.104-111, 1963. 